Covid-19 como obstáculo epistémico: Hacia una matriz de la cui-dadanía (0 ecología de los cuidados). Notas en movimiento

\author{
Covid-19 as an Epistemic Obstacle: Towards a Care-Matrix (or Ecology of \\ (are). Notes in Motion
}

\section{Ruth Sosa}

Ruth Sosa es docente e investigadora de la Escuela de Trabajo Social, Facultad de Ciencia Política y Relaciones Internacionales, Universidad Nacional de Rosario, Argentina.

E-mail: ruthsosaunr@gmail.com

\section{resumen}

La irrupción del Covid-19 en nuestras vidas se instala como un estado de excepcionalidad disruptivo que trastoca nuestra corriente cotidianeidad. La perplejidad e incomodidad de esta nueva condición hace que vivenciemos este momento como profundamente incómodo, en suspensión, en tanto aquello que avizoramos en el futuro mediato e inmediato está pletórico de incertidumbres e imprevisibilidad. El borde de "lo real" parece estar desplazado. La "con-fusión" entre "lo público" y "lo privado" se vuelve una suerte de "fisura". De allí que se configuran obstáculos y rupturas de ciertos órdenes sociales que alteran nuestras vidas y expectativas, interpelando gramáticas, semánticas, y también instituciones y convenciones discursivas. Entre esas interrogaciones, se profundiza la interpelación hacia el propio concepto de democracia y ciudadanía. La matriz del cuidado, abrazada y potenciada por los feminismos en sus alianzas y apuestas en la esfera de lo subterráneo y desde las calles, nos viene sugiriendo nuevos sentidos y una llave teóricoepistemológica entrañablemente política.

\section{palabras clave}

epistemología / incertidumbre / feminismos / cui-dadanía

\section{summary}

The irruption of Covid-19 in our lives is installed as a state of disruptive exceptionality, disrupting our daily current. The perplexity and discomfort of this new condition makes us experience this moment as deeply uncomfortable, in suspension, while what we envision in the immediate and immediate future is full of uncertainties and unpredictability. The edge of "the real" seems to be displaced. The "confusion" between "public" and "private" becomes a kind of "fissure". Hence, obstacles and ruptures of certain social orders are configured that alter our lives and expectations, challenging grammars, semantics, and also discursive institutions and conventions. Among these questions, the interpellation towards the very concept of democracy and citizenship is deepened. The matrix of care, embraced and empowered by feminisms in their alliances and bets in the sphere of the underground and from the streets, has been suggesting new meanings and an endearingly political theoreticalepistemological key.

\section{keywords}

epistemology / uncertainty / feminisms / carematrix 
"La lengua tiene un cuerpo y el cuerpo tiene una lengua. No obstante, el mundo se funda en aquello que en el cuerpo no es lenguaje (lo moral) y lo que en el lenguaje no es cuerpo (lo carente de expresión)" Benjamin (2017: 210).

\section{I - El Covid-19: La cuarta herida narcisista. Trauma colectivo y miedo al derrumbe}

En 1917 Freud publica "Una dificultad del psicoanálisis", en la que refiere a las tres heridas narcisistas de la humanidad. De alguna manera, el mentor del psicoanálisis argumenta que no somos dueños de nuestra propia casa tras descubrir el inconsciente. La pandemia de Covid-19 pareciera ser algo como la cuarta herida narcisista de la humanidad, en tanto, una vez más, como humanos nos vemos empequeñecidos frente a imperativos exógenos. Por otro lado, se hace notorio cuando los seres humanos, que tenemos la fortuna de tener una casa en donde alojarnos, parecemos no comprender la necesidad de confinarnos para prevenir la expansión del virus que puede circular con nuestros cuerpos andantes.

Los comportamientos infractores -y no digo transgresores, porque la transgresión es una rebeldía reivindicatoria que apuesta políticamente a trazos transformativos colectivos (Ulloa, 2012)- se pueden ver en los modos desafiantes de conductas ventajistas que se respaldan en el discurso de las libertades individuales. En esta línea, es posible constatar cómo las formas ideológicas de la apelación a la libertad individual confrontan con el cuerpo-sujeto-colectivo (Bialakowsky et al., 2020), y nos ponen, así, en situación de riesgo sanitario.

Estamos en el paisaje de una pandemia que nos impone otro modo de vivir y de socializarnos. También otro modo de morir y de canalizar duelos, en soledad y aislamiento. Nos hallamos inmerses en una fisura. Los tiempos y espacios normalizados por las ficciones reguladoras de la modernidad hoy están desquiciados. Esta fisura, que por veces se cristaliza en un "non-sense", lleva la marca incisiva de una suerte de desquicio. De este modo, la prominencia de dudas, incertezas e incertidumbres con relación a la normalidad que conocimos hace que vivenciemos el presente como un trauma colectivo.

Si bien no todos los seres humanos asumimos y llevamos el estado de confinamiento y aislamiento de igual modo y con igual efecto e impacto, hay para quienes esta condición es muy difícil de sobrellevar, y representa enormes costos subjetivos y emocionales. Hay múltiples expresiones de sufrimiento emanadas de resistencias a los hábitos obligados por la pandemia. Para quienes es trabajoso sobrellevarla, esta situación de traumatismo de origen colectivo entra en resonancia con conflictos subjetivos personales que son externos a cada ser humano en particular.

El virus es el miedo. De alguna manera, hay un "miedo al derrumbe", lo que alberga, un miedo al vacío, o el mismo miedo a la muerte. El "miedo al derrumbe" es algo que en 1963 pudo nombrar el heterodoxo psicoanalista Donnald Winnicott al definirlo como una "falla en la organización de las defensas". ¿Qué es lo que 
está subyacente, por debajo, del sistema de defensas en los humanos? El autor dirá que "el yo organiza defensas contra el derrumbe de la organización yoica, que es la amenazada, pero nada puede organizar contra la falla ambiental en tanto y en cuanto la dependencia es un hecho viviente" (Winnicott, 2015: 113). De allí que el ambiente facilitador es un sostén, y el miedo al derrumbe supone, en alguna medida, un miedo a un derrumbe ya experienciado. Puede ser identificado como un miedo a un hecho pasado que aún no fue experienciado. Ahora bien, ¿qué nos ocurre subjetiva y colectivamente si ese ambiente se desestabiliza? ¿De qué modo agenciamos nuestros miedos? ¿Seremos capaces de convivir con ese vacío de ciertas ausencias que arrastra el Covid-19? Porque en las ausencias se incluye el duelo frente a la pérdida de la "normalidad" que ya no es. ¿Cómo nos construimos una ética y una estética del derrumbe?

Hemos de tomarnos el trabajo de pensar, para elaborar nuestros traumas en medio de este pasaje de suspensión de nuestros cuerpos, para que no caigamos en la repetición de lo mortífero, de la normalidad que ya conocimos que, junto a su necro-política, nos trajo hasta aquí. Vale decir, asumirnos el trabajo en los "territorios del pensar" (Zemelman, 2007; Wainsztok, 2020) desde el saber de nuestros cuerpos vibrátiles (Rolnik, 2019), nuestros sentires, percepciones, sensaciones y co-razones.

"La ciencia" y "la verdad" que conocimos nos llevaron a enormes atrocidades y traumas colectivos como guerras, genocidios y dictaduras con desaparición forzada y tortura de personas. Las epistemologías críticas desde la Escuela de Frankfurt hasta las feministas del presente nos vienen aleccionando sobre el vínculo peligroso entre conocimiento e interés y, fundamentalmente, entre conocimiento y poder. Cabe, por tanto, en nuestra condición de profesores, académicxs e investigadores preguntarnos incesantemente cuál es el sentido político del conocimiento que construimos, justificamos y legitimamos con nuestras prácticas corrientes, y a quiénes aventajan nuestras producciones científicas y las políticas públicas que promovemos.

La pregunta que hemos de hacernos es: ¿a qué normalidad queremos volver? Esto nos induce a tomarnos el trabajo en los territorios del pensar, del saber, y asumir una interrogación ética en este tiempo, que es un tiempo de profundo desamparo. En medio de este aparente absurdo "non-sense", y de esta con-fusión entre lo público y lo privado, vale desafiarnos a empezar a pensar, no en definiciones que acuartelan y encorsetan, sino en "infiniciones" para traer a Lévinas (2002). Inmerses en los borramientos de los límites entre los tiempos del trabajo y del ocio, hemos de reflexionar acerca de qué normalidad nos vamos a hacer los seres humanos tras elaborar este trauma colectivo inédito, y de carácter planetario.

De alguna manera, el Covid-19 nos arrincona y nos obstaculiza hacia un individualismo epistémico que se desborda hacia múltiples dimensiones sociales. Incluye todo un espectro de prácticas biopolíticas (Foucault, 1998), hasta las necropolíticas, desnudando opacadas segregaciones y desigualdades, sean de género(s), étnico-raciales, de clases sociales. Tal es así que homicidios raciales y étnicos, como el de George Floyd en Estados Unidos, o como las violencias ocurridas en la 
comunidad qom en el norte chaqueño, en el marco del confinamiento, son apenas el ápice de una muestra flagrante de las violencias institucionalizadas en nuestros sistemas "democráticos", que tienen como efecto manifestaciones multitudinarias de indignación en las diferentes latitudes del planeta. De este modo, el "intelecto social", en términos de la vida de la "mentalidad pública-subjetiva-social", queda resonando y, en alguna medida, interpelado (Bialakowsky et al., 2020).

¿A qué normalidad nos vamos a desafiar para que sea una garantía de con-vivir en un mundo habitable (Butler, 2017), en un ecosistema sustentable que cuide la vida? Hacerse incesantemente esta pregunta supone pensar qué normalidad puede contrarrestar a la actual necro-política y pensar colectivamente, en "co-razones" para hacernos de ficcionalidades co-reguladoras, capaces de abrazar el cuidado de la vida.

\section{II - "Con-fusión": La política de nuestras casas. Intimidades estalladas}

La "normalidad" distópica que estamos viviendo tras la irrupción del Covid-19 es un mundo hiper-virtualizado, en el que, para quienes tenemos casa y tecnologías adecuadas, todo se hace desde nuestro lugar de alojamiento: trabajamos en y desde casa, tenemos clases en casa, nos hacemos de las compras desde nuestra casa, nos vinculamos con otres desde la remoticidad. El mundo propio de hoy es la "con-fusión" entre lo público y lo privado. Se preguntará Carla Wainsztok (2020), “'estamos expulsados a nuestros hogares o estamos impulsados a éste?” Lo privado parece desvanecerse, tornarse pequeño por estos tiempos al punto que necesitamos el derecho a la desconexión. Eva Illous (2020) apunta que la crisis de la pandemia forzó a las familias a permanecer en un estado de implosión interior.

La obra del artista español Javier Jaén ${ }^{1}$, publicada en una bella serie denominada Postales del Coronavirus del New York Times nos muestra cómo nuestras casas se han ampliado como consecuencia del traslado de nuestras actividades del "afuera" hacia el "adentro". Nuestras casas han multiplicado sus usos durante la pandemia: además de ser el lugar indiscutible donde nos alojamos y descansamos, la casa es hoy taller, gimnasio, oficina, local de venta, escuela, aula para aprender, aula para enseñar. La pandemia ha cambiado nuestro vínculo con nuestra casa. La casa, el lugar históricamente atribuido como del orden de lo no-político (Bachelard, 2010; Chollet, 2017), y asignado culturalmente para las mujeres, ha adquirido una nueva centralidad para quienes hoy la habitan durante todo el día.

Esta ampliación de funcionalidades de la casa es posibilitada por grandes empresas que controlan y desarrollan tecnologías para navegar en el mundo desde el lugar que habitamos. Eva Illouz (2020) plantea que el virus propulsó vertiginosamente esta tendencia hacia adelante, en tanto en solo tres meses se entablaron procesos que hubieran precisado de unos quince años en países desarrollados.

$\mathrm{Si}$ antes disfrutar de "quedarse en casa" estaba asociado a poder singularizarse, y librarse de la mirada y del control social (Chollet, 2017), hoy eso parece estar cuestionado.

Los binarismos construidos en la modernidad se encuentran tambaleando, en tanto en nuestras casas acontece una multiplicidad de dimensiones de la vida so- 
cial que hasta el momento de esta disrupción ocurrían fuera de nuestros ámbitos doméstico-privados. Hoy nuestra casa es un lugar de deliberación política y de una nueva reconfiguración de las relaciones sociales entre los géneros. Las tensiones derivadas entre responsabilidades familiares y laborales, que se focalizaban en las identidades femeninas, hoy desafían la masculinidad hegemónica. Esta condición traería indicios concretos para reconfigurar las relaciones sociales de género(s) en la vida de nuestras sociedades de la postpandemia. Del mismo modo, la idea de responsabilidad se ha trastocado, tanto en el "afuera" como en el "adentro". En el "afuera" porque hemos de contar con otres para evitar contagios, así como nosotres hemos de cuidar a otres para obturar la circulación del virus. Porque el cuidado y la responsabilidad social compartida son directamente proporcionales al esfuerzo sanitario para controlar los brotes. En el "adentro", debido a la circunstancia de que todes estemos en casa "trabajando", visibiliza también el peso interminable y latente del trabajo reproductivo, con lo cual "estar en casa" no es -como no lo ha sido- sinónimo de estar en situación de "desocupación " o en estado de ocio. Por otra parte, la casa nos ha hecho notar, una vez más, cómo es el espacio en el que se condensan las múltiples aristas de las violencias de género. De este modo, hay quienes están lejos de sentirse segures en su propia casa. Nuestras intimidades se encuentran estalladas. Emociones y cuerpos desbordan por la crisis, muchas de ellas pre-existentes, hoy potenciadas por la pandemia.

\section{III - La crueldad del capitalismo contemporáneo y la crisis de las democracias representativas}

Enrique Dussel (2020) interpreta la pandemia como "un búmeran que la Modernidad lanzó contra la Naturaleza". Problematiza ciertas postulaciones que intelectuales reconocidos del mundo académico ofrecieron tempranamente en el marco del ASPO (Aislamiento Social, Preventivo y Obligatorio) y argumenta que

estamos viviendo por primera vez en la historia del cosmos, de la $\mathrm{Hu}-$ manidad, los signos del agotamiento de la Modernidad como última etapa del Antropoceno, y que permite vislumbrar una nueva Edad de Mundo, la Transmodernidad en la que la Humanidad deberá aprender, a partir de los errores de la Modernidad, a entrar en una Nueva Edad del Mundo donde, partiendo de la experiencia de la necro-cultura de los últimos cinco siglos, debamos ante todo afirmar la Vida por sobre el capital, por sobre el colonialismo, por sobre el patriarcalismo y por sobre muchas otras limitaciones que destruyen las condiciones universales de la reproducción de esa Vida en la Tierra (Dussel, 2020: 1, cursivas en el original).

El Covid-19 pone al desnudo la necro-política que nos hemos erigido tras recurrentes ensayos de neoliberalismo y de un capitalismo cuyo rasgo sobresaliente es el extractivismo. Ha puesto sobre relieve no solamente la crisis de las democracias representativas que vienen siendo cuestionadas desde las últimas décadas a nivel global, sino también los "modelos" de protección social, de derechos y de ciudadanía que se han ensayado en diferentes contextos y territorios geopolíti- 
cos. El modo en el que los sistemas democráticos han canalizado la justicia en su dimensión social, económica (distributiva), cultural (reconocimiento) y política (representativa) (Fraser, 2008) viene siendo profundamente interpelado.

Ya queda corto y anacrónico hablar en términos de "exclusiones". La brutalidad y complejidad del mundo global nos revela las insistentes crónicas de "expulsiones" (Sassen, 2015) de un "sistema-mundo" (Wallerstein, 2005) cuyo impacto, lejos de ser reductible a la creciente desigualdad y desempleo, se amplía con la aseveración de fundamentalismos, racismos, e intolerancias (Eco, 2019), con el crecimiento de poblaciones desplazadas, encarceladas junto a la destrucción de la tierra, del agua y del ecosistema como un todo.

Estos movimientos crueles y tanáticos del capitalismo vienen generando una aseverada crisis de legitimidad de las instituciones que lo sostienen. De alguna manera, pensar en la necro-política es asumir que estamos ante sistemas institucionalizados que matan -violencia policial, por ejemplo- y sistemas institucionalizados que dejan morir, como los Sistemas de salud privados y privativos. Esta condición erosiona la legitimidad social y política de nuestras democracias.

De acuerdo con Manuel Castells (2017), la crisis de legitimidad de los regímenes democráticos implica una ruptura, en términos de desconexión en los mecanismos de representación política. Se cristaliza en una disrupción subjetiva del conjunto de la ciudadanía con relación a sus representantes políticos que no consigue suturar mediante la pluralidad de opciones político-partidarias en los procesos electorales. El autor nos alerta acerca de emociones colectivas como la decepción, la desidia y la indignación, como los sentimientos que aparecen en la ciudadanía, vinculados a una política cada vez más comprometida y expuesta a los aparatos mediáticos, en tanto descrédito de la confianza en el sistema democrático, en una incesante globalización del capital y ampliación del Estado-red. Por otro lado, esa ruptura entre gobernantes y gobernados se configura en un contexto en el que se pone en cuestión la habitabilidad para los seres humanos en el planeta, derivada de la acción dañina de los humanos, asociada a la incapacidad consciente para detener esta tendencia destructora del ecosistema. Castells contrasta el avance tecnológico con el subdesarrollo ético-político. A su vez, actualiza la idea weberiana de que la historia enseña que las grandes transformaciones han venido junto con las nuevas mentalidades emergentes ante la opresión y el autoritarismo. Para Castells, es indudable la transformación de la cosmovisión de las sociedades del presente.

\section{IV - O inventamos o nos repetimos en el error de lo mortífero: Hacia una matriz de la cui-dadanía (o ecología de los cuidados)}

El concepto de cui-dadanía lo escuché de Denise Najmamovich (2019) y me pareció sugerente, feminista; genuino y revolucionario; ético y estético; subterráneo, anfibio, entrañable. No se trata de un error sintáctico, sino de la apuesta hacia una nueva semántica y una gramática otra. Son derivas de una resemantización que alcanza la propia matriz estatal para pensar y producirnos un derecho -que muy bien puede ser izquierdo, o en otras direcciones poco conocidas y explora- 
das- universal, que supere la lógica androcéntrica, patriarcal, colonial, racial de la tradición histórica de la ciudadanía.

La propia idea de democracia representativa, y manipulada por los poderes fácticos, ya resulta anacrónica, pues ella derivó de una ciudadanía selectiva y privilegiada. Por lo tanto, hoy es insuficiente y pobre para albergar una nueva matriz estatal, que sea capaz de alojar los retos del presente. El estatus de ciudadanos reunía, en la polis griega, a hombres, libres y blancos. Luego, a lo largo de la modernidad, se instalará el concepto liberal de ciudadanía. Se trata de un concepto que desde hace mucho tiempo viene dando evidencias de su sesgo tanático y necro-político, por destilar una semántica androcéntrica, colonial, racial y capitalista, por estar cargado de un individualismo epistémico y de una racionalidad meritocrática. Esta connotación alcanza aun a la "ciudadanía social" que, de alguna manera, compensa en términos de "justicia redistributiva" pero sin cuestionar desde lo profundo un sistema intrínsecamente lucrativo que, en su enunciación formal, política y cívica, se inscribe en la tensión entre libertad e igualdad.

La cui-dadanía, en cambio, nace de una (vital) equivocación, o de un lapsus, o quizá de un desvío, o una digresión. Se trata de una suerte de línea de fuga. Sin romantizar el concepto, nace de aconteceres sororos y solidarios de cuerpos congregados en los cuidados; de cuerpos aliados y de lucha política en las calles (Butler, 2017). En todo caso, emerge de un error vital que viene al rescate del ancestral atesoramiento de los cuidados que las mujeres hemos sabido sostener y aquerenciar con nuestros cuerpos a nivel planetario y a lo largo de la historia de la humanidad. Algo más universal que los cuidados, y por efecto, la cui-dadanía es difícil de encontrar. De allí que me interesa instalar la necesidad de hacernos de esta ética. De una nueva gramática, la de la "ecología de los cuidados" (Najmanovich, 2019), que ha de penetrar la nueva matriz estatal, así como también la fundamentación de los conocimientos, entre ellos, el científico. Porque la cui-dadanía está centrada en la sostenibilidad de la vida.

El modo en que construimos comunidades de saber presupone la manera en que integramos sociedades (de ningún modo las hemos de asimilar a la imagen y semejanza de "modelos" hegemónicos). Sucede que los seres humanos somos simultáneamente iguales y diversos. Construimos en el sentido de que las voces y cuerpos múltiples y diversos se construyan desde el derecho a las disidencias, coincidencias e intersecciones. Así construimos comunidades políticas y comunidades científicas.

El feminismo nos viene proponiendo un concepto clave, que es histórico y que hoy no podemos soslayar: el cuidado de la vida y la sostenibilidad de la vida. Una evidencia de esto es que la humanidad no habría sobrevivido sin la contribución de las mujeres a la reproducción y al cuidado de la vida. Esto ha de acompañar un énfasis en la crítica hacia un sistema de valores y de ejercicio del poder que menosprecia y devalúa las actuaciones en el ámbito doméstico vinculado a la vida de convivencia cotidiana. De este modo, esa lectura crítica nos induce a hacernos una autocrítica de nuestros propios hábitos de vida y de pensamientos, así como de sus modos de crearlos y justificarlos. 
Frente a la actual revelación del obstáculo del individualismo epistémico, potenciado por la crisis del Covid-19, nos vemos ante la imperiosa necesidad de un replanteo que alcanza tanto nuestro paradigma científico como la cosmovisión del mundo y de la vida. Este obstáculo epistémico devela lo invisible de la dominación ideológica instituyente del intelecto social, que articula la colonialidad del poder, el sistema productivo capitalista y el patriarcado cultural. De allí la urgencia de desnudar los equívocos y las ideologías subyacentes en la ciencia y en la razón que le es inherente. El carácter destacado de este obstáculo epistémico es que ha impactado en una zona de la ciencia, en toda su estructura, y que obliga a ceder en sus hegemonías. El caso más conspicuo en el campo de la salud, con la emergencia de la pandemia, ha ofrecido en el paisaje global un giro desde la hegemonía de la atención médica individual a la consideración sanitaria de la salud pública-colectiva (Bialakowsky et al., 2020).

Desde ese paradigma de la cui-dadanía hemos de situarnos para co-construir pensamiento derivado de una praxis sociopolítica a favor de la vida desde una trama que nos construya una vida en común. Hemos de re-co-inventar conceptos otros, a modo de infiniciones: la democracia y la ciudadanía moderna ya no nos contienen ni nos referencian. En contraposición, nos encontramos ante el desafío de seguir abriéndonos a la creación de un movimiento de responsabilidad ética hacia el Otro. Porque ese Otro, en su sentido profundo, son quienes padecen física, psíquica y espiritualmente (Lévinas, 2002) los trazos de un sistema institucionalizado que es devastador y extractivista, es decir, necropolítico.

El feminismo latinoamericano -así como las comunidades culturales subalternativizadas en los centros del capitalismo- nos viene proporcionando herramientas críticas e inagotables para deconstruir y desentramar las formas de dominación y de opresión que aún perviven en nuestras sociedades. Ante esta interrupcióndisruptiva del Covid-19, son momentos de leer y escuchar. De ninguna manera tenemos que desperdiciar energías en explicar desde un feminismo teórico y vacío que, en reiteradas ocasiones, ha producido en ausencias e ignorancias de las múltiples identidades que interseccionan lo femenino (Maffía, 2020).

Hoy, el Covid-19 interpela y reta nuestros cuerpos. Conceptos y categorías que se fueron labrando en la modernidad hoy están siendo tambaleadas y sacudidas fuertemente tras un largo período de confinamiento en nuestras casas. De ese reto deviene de-construir binarismos tanáticos que ha construido la modernidad occidental con sus lógicas de opresión y dominación. Nuestros cuerpos, que son territorios de vida, nos desafían con nuevas incertezas e incertidumbres. Los feminismos siguen abriendo teorías que tensionan e incomodan. El conocimiento avanza en esa incomodidad y tensión. El conocimiento no puede avanzar en la complacencia, que es repetición.

De algún modo, pensar en clave de epistemologías críticas vitales desde lo común es desentrañar la urdimbre, desentramar el subyacente lenguaje que se reviste como universal y neutro. La violencia epistémica se trasluce en un lenguaje sin cuerpo; un lenguaje que no está situado (Haraway, 1995), sino que pretende ser una universalidad irrefutable. El concepto de ciudadanía tiene ese problema de 
raíz. De allí la apuesta por la cui-dadanía, una semántica que tiene y se asume con y desde un cuerpo, que es singular y es colectivo.

Hemos de seguir a pasos -aunque pequeños- firmes y genuinos, y con la autocrítica permanente y la sororidad valiente que nos peculiariza, en este seguir abriendo teoría que no puede erigirse como un corset encasillador, sino como una teoría alumbradora y referente de la vida, un entramado desde el subterráneo -pero no menos revolucionario- confinamiento, hasta la red que nos constituye en las políticas de las calles. Hemos de continuar la trama que nos construye como comunes en nuestras diferencias, en un mundo que, hoy más que antes, parece sugerir que la construcción colectiva de la agenda política ha de tener alternancia entre lo virtual y lo corpóreo.

\section{Referencias}

1. Diario New York Times. Columna-Serie Postales del Coronavirus (2/4/2020). Disponible en: https:// www.nytimes.com/es/2020/04/02/espanol/opinion/postales-del-coronavirus.html

\section{Bibliografía}

Bachelard, G. (2010). Poética del espacio. Ciudad de México, México: Fondo de Cultura Económica. Benjamin, W. (2017). La tarea del crítico. Buenos Aires, Argentina: Eterna Cadencia.

Bialakowsky, Montelongo, L. y Sosa, R. (2020) El papel de la autoría colectiva y las instituciones y centro de investigación ante la pandemia del Covid-19. Cuadernos abiertos de crítica y coproducción 2. Buenos Aires, Argentina: CLACSO.

Butler, J. (2017) Cuerpos aliados y lucha política: hacia una teoría performativa de la asamblea. Barcelona, Paidós.

Castells, M. (2017). Ruptura. La crisis de la democracia liberal. Madrid, España: Alianza.

Chollet, M. (2017). En Casa. Buenos Aires, Argentina: Hekht.

Dussel, E. (2020). Cuando la Naturaleza jaquea la orgullosa modernidad. Disponible en: http://viajederetornosigloxxi.blogspot.com/2020/04/cuando-la-naturaleza-jaquea1-la.html?m=1

Eco, U. (2019). Migración e intolerancia. Buenos Aires, Argentina: Lumen.

Foucault, M. (1998). Microfisica del poder. Madrid, España: La Piqueta

Fraser, N. (2008). Escalas de Justicia. Barcelona, España: Herder.

Freud, S. (1978). Una dificultad del psicoanálisis. En S. Freud, Obras Completas, vol. XVII. Buenos Aires, Argentina: Amorrortu.

Haraway, D. (1995). Ciencia, cyborgs y mujeres. La reinvención de la naturaleza, Madrid, España: Cátedra.

Lévinas, E. (2002). Totalidad e Infinito: ensayo sobre la exterioridad. Salamanca, España: Sígueme.

Najmanovich, D. (2019). Cuidadanía. Ecología de los saberes y cuidados. XVI Jornadas Nacionales de la Red de Psicopedagogía Garrahan. Buenos Aires, Argentina. Disponible en: https://www.youtube. com/watch?v=u9YSSmGTmEQ

Maffía, D. (2020). Feminismo y epistemología. En D. Maffía et al., Cuadernos Feministas para la transversalización. Apuntes epistemológicos, pp. 17-30. Rosario, Argentina: UNR Editora.

Rolnik, S. (2019). Esferas de la Insurrección. Apuntes para descolonizar el inconsciente. Buenos Aires, Argentina: Tinta Limón.

Sassen, S. (2015). Expulsiones. Brutalidad y complejidad en la economía global. Buenos Aires, Argentina: Katz.

Ulloa, F. (2012). Salud ele-Mental. Con toda la mar detrás. Buenos Aires, Argentina: Libros del Zorzal.

Wainsztok, C. (2020) Gramáticas y cartografías del sur. Revista Movimiento. Disponible en: http:// 
www.revistamovimiento.com/ensayo/gramaticas-y-cartografias-del-sur/

Wallerstein, I. (2005). Análisis de sistemas-mundo. Una introducción. Ciudad de México, México: Siglo XXI.

Winnicott, D. (2015). Exploraciones Psicoanalíticas I. Buenos Aires, Argentina: Paidós.

Zemelman, H. (2007). El ángel de la historia. Determinación y autonomía de la condición humana (Idea para un programa de Humanidades). Barcelona, España: Anthropos.

Ruth Sosa, "Covid-19 como obstáculo epistémico: Hacia una matriz de la cui-dadanía (o ecología de los cuidados). Notas en movimiento". Revista Temas y Debates. ISSN 1666-0714, año 24, número especial, julio-diciembre 2020, pp. 117-126. 